\title{
Limitaciones de la metáfora de la inmersión en la comprensión de novela e Internet como espacios virtuales análogos
}

\section{(Limitations of the metaphor of immersion to understand the novel and the Internet as analogous virtual spaces)}

\author{
Enrique FERRARI NIETO
}

Recibido: 12 de abril de 2011

Aceptado: 22 de septiembre de 2011

\section{Resumen}

Los primeros estudios que sondearon la tecnología digital desde la filosofía no precisaron los rasgos distintivos de sus incipientes materializaciones. Tomando solo el referente de la realidad virtual, recuperaron la inmersión como metáfora básica, de manera análoga a lo hecho anteriormente con la novela.

Internet, de este modo, ha sido comprendido como virtualidad (cerca de Baudrillard); en lugar de vincular su sistema hipertextual a teorías más próximas (Deleuze y Guattari, Bourriaud) que no eluden su conexión necesaria con lo real.

Palabras clave: autonomía, marco, imagen, hiperrealidad, hipertexto, rizoma.

\begin{abstract}
The first studies in Philosophy that studied digital technology did not specify the characteristics of its various technical applications or instruments. They looked at the virtual reality and used the metaphor of immersion to study the set of all technological developments, as had been done before with the novel.

Thus, Internet is misunderstood by many experts as virtuality (next to Baudrillard), rather than linking its hypertext system closer to other theories like those proposed by Deleuze and Guattari or Bourriaud.
\end{abstract}

Keywords: autonomy, frame, image, hyperreality, hypertext, rhizome. 


\section{Introducción}

Para el arte y la novela, la metáfora de la inmersión, aunque muy intuitiva, ha perdido legitimidad como explicación de la relación que se establece entre el espectador y la obra. En principio porque la exigencia al espectador de que adopte una posición más crítica, más participativa, en su experiencia estética -muy común en las teorías estéticas del siglo $\mathrm{XX}$-, choca frontalmente con la actitud pasiva que evoca esa metáfora: simplemente dejarse embaucar por el contenido de la obra de arte, dejarse hacer. Pero también -aquí más importante- por el recorrido tan corto que tiene la imagen de la inmersión para poder explicar, con una solidez filosófica, esa comunicación entre sujeto y obra.

Con todo, consumado hace ya tiempo su desahucio para la novela (la manifestación artística donde mejor cuajó) ${ }^{1}$, propuestas teóricas relevantes, con mucho eco, han querido rescatar para Internet esta metáfora, sin atender a los problemas de su aplicación anterior. Porque con la inmersión resuelven alegremente, sin mayores disquisiciones, el modo de acceder a Internet -al trasladarse el usuario de un lugar a otro- en esta alegoría intuitiva que entiende la red como un espacio diferente a lo real, diferente al que habita (físicamente) el usuario, al obviar su operatividad y mecanismos internos. Como antes la obra de arte pretendidamente autónoma, aislada del mundo de la praxis, Internet se les aparece como un "mundo", que requiere, para quedar sellado herméticamente, un elemento que lo separe de la realidad, de lo otro: el marco de un cuadro, en la estética de Ortega, por ejemplo.

Pero la metáfora de ese mundo separado, con sus límites, anterior a la de la inmersión, es tan ingenua, es tan deficitaria para un argumento sólido, que al plantearlo en su convergencia con la ontología (como pide su terminología) no puede mantenerse en pie: Se agota antes de dar las respuestas inevitables sobre su generación y sus fronteras. Aunque la reflexión de estas propuestas no busca llegar tan lejos: se reorienta antes hacia lo meramente epistémico. Como premisa en su crítica, la imagen de la inmersión fortalece la concepción falaz de Internet como un mundo aparte para, desde ahí, desde la reclamación de una separación clara, tangible, que no puede darse, entre Internet y lo real (el marco de Ortega), arremeter contra la confusión que lo virtual y lo real generan en el usuario, convertido (forzado a convertirse) en un Segismundo digital.

\section{Las pautas de la comprensión de la acción del lector como inmersión}

Internet, con una definición estándar, muy básica, es un conjunto descentralizado de redes de comunicación interconectadas. Pero al abrirse en muy pocos años a

\footnotetext{
${ }^{1}$ La novela, en la que el contenido artístico se muestra más explícito, más accesible, facilitaría esa impresión de la inmersión del lector en la trama.
} 
la teoría un campo tan vasto para la investigación como la tecnología digital, con las entrañas de la red, que constituyen, con esa imagen tan exitosa, todo un mundo, muchos teóricos se precipitaron con la elección de una base teórica en torno a su (inmediatamente asignada) condición virtual: Un tema de largo recorrido en las bellas artes que en la mayoría de estos trabajos ha sido retomado tal cual, como un primer pilar que ya estaba ahí, para su aplicación a las nuevas tecnologías; en vez de volver a repensarlo debidamente como condición de una materia con más posibilidades o al menos con más frentes que la literatura o la pintura, como intermediario y como la realidad misma.

El contenido que genera a gran velocidad la tecnología informática ha desbordado la capacidad de la producción crítica y teórica ${ }^{2}$, que se ha visto ante demasiados problemas inexplorados como para detenerse, con la expectación ante lo nuevo instigándola, en uno aparentemente ya resuelto: su carácter virtual (signifique esto lo que signifique para el caso concreto de Internet), de la que parten o bien con una advertencia o bien con una exaltación para fijar su posición, en contra o a favor de un determinado efecto de la tecnología digital. Pero la reflexión mayoritaria que subyace y que pocas veces se hace explícita es la comprensión de lo virtual desde su efecto de inmersión en el usuario, al vincular lo virtual con la simulación, con la apariencia de lo real de lo que no es real. Hay otras posibilidades para entrar en lo virtual que no limitarían tanto las posibles funciones de la tecnología digital (la virtualidad real de Castells, por ejemplo). Pero esta de la inmersión es un efecto de las artes que tiene en el análisis teórico un bagaje demasiado grande para que no pese en nuevas propuestas.

Para mi argumento (no pretendo aquí ser exhaustivo, sino mostrativo) basta con apuntalar transversalmente su recorrido con unas pocas cotas con las que la novela ha llegado a converger con la ontología. La primera: Platón, que condena el arte porque se ve obligado por el dualismo ontológico de los dos mundos que se inventa para salvar a Parménides del panta rei: Por ser únicamente mímesis, por tanto copia de la copia que es el mundo sensible: alejado dos veces de la verdad, de la idea. Solo por eso: para encajar las piezas. En su gradación del ser lo dejó como el último peldaño, el más bajo, solo una imagen, una apariencia, en su propuesta de una filosofía soberana alejada del discurso poético. Con lo que lo tuvo que descartar también para el conocimiento: porque el espectador, absorto con la obra, podría confundirla con la realidad, con esa consecuencia epistémica primera de la inmersión, que no hace explícita: como la pérdida de la capacidad crítica, de esa conciencia de estar no ante la realidad sino ante su copia. Una condena por ilusionista que, incluso hoy, sigue vigente en unos pocos planteamientos estéticos, después de haber conseguido mantenerse como una referencia teórica importante, unas veces más escorada y otras menos. También con su carga moral, en el ilustrado Rousseau, por

\footnotetext{
2 Cf. Castells (2001), p. 17.
} 
ejemplo, en su Carta a D'Alembert sobre espectáculos, en la que rechaza el teatro que se limita a reflejar con su imitación las costumbres dominantes, porque entiende (como ha explicado Jauss) ${ }^{3}$ que ese teatro puede llevar al público a asimilar, a afirmar, esa mala situación.

Pero en seguida Aristóteles, con su Poética, le restituye el valor al arte, a la poesía $^{4}$. No cuestiona su función mimética -todas las artes son imitación, dice-. Pero la revaloriza como procedimiento cognitivo en tanto que queda legitimada por la propia naturaleza del hombre, que aprende imitando; que aprende, visto en el arte, lo que podría ser. Básicamente una cuestión epistemológica con la que engancha el argumento de su maestro. Pero para ese encuentro posible entre la obra y el lector o espectador circunda ya la noción de inmersión. Centra el efecto de la obra en la capacidad del espectador de adentrarse en ella para, con la catarsis, experimentar, vivir de algún modo, lo representado, pero sin las consecuencias de lo real: Para poder, con esa inmersión, vivir simuladamente las vidas de los personajes, hasta cambiar su propia vida.

Como también lo hace Cervantes con el Quijote, que se postula, con el caso de su protagonista y las apreciaciones del narrador, como una reflexión metaliteraria en torno al uso que puede hacer el lector de la ficción. La tradición medieval apostaba, con el exemplum, por una función didáctica para la literatura, con una aplicación directa de lo leído en la realidad, como si fuera un ejemplo. Pero Cervantes, en los inicios del XVII, se desmarca y avisa al lector de que sus novelas no son más que un entretenimiento. Lo avisa en el prólogo con ese Desocupado lector con el que empieza, que enlaza más tarde con el de sus Novelas ejemplares: "Y así te digo otra vez, lector amable, que destas novelas que te ofrezco, en ningún modo podrás hacer pepitoria, porque no tienen pies, ni cabeza, ni entrañas, ni cosa que les parezca"5. Y lo lleva luego a la trama, sufriendo su protagonista, un pobre hidalgo manchego, las consecuencias de una lectura errónea, incapaz de entender su espacio y su función. Se lo presenta al lector: "Los ratos que estaba ocioso, que eran los más del año, se daba a leer libros de caballerías, con tanta afición y gusto, que olvidó casi de todo punto el ejercicio de la caza, y aun de la administración de su hacienda"6. Con los efectos en su equilibrio mental: "Él se enfrascó tanto en su lectura, que se le pasaban las noches leyendo de claro en claro, y los días de turbio en turbio; y así, del poco dormir y del mucho leer, se le secó el celebro de manera que vino a perder el juicio. Llenósele la fantasía de todo aquello que leía en los libros..."7. Para, al final de la novela, antes de morir, devolverle la cordura para que

\footnotetext{
${ }^{3}$ Cf. Jauss (2002), p. 48.

4 Cf. Aristóteles (2004), cap. III, 7.

5 Cervantes (2000), tomo I, p. 51.

6 Cervantes (1998), p. 37.

7 Cervantes (1998), p. 39.
} 
pueda él mismo arremeter contra los libros que lo enloquecieron: "Yo tengo juicio ya, libre y claro, sin las sombras caliginosas de la ignorancia que sobre él me pusieron mi amarga y continua leyenda de los detestables libros de las caballerías. Ya conozco sus disparates y sus embelecos y no me pesa sino que este desengaño ha llegado tan tarde que no me deja tiempo para hacer alguna recompensa, leyendo otros que sean luz del alma" 8 .

Dos posturas extremas, tanto esta rectificación, esta vuelta al exemplum, como la locura anterior, que son los dos modos desacertados equidistantes de la lectura que propone Cervantes, en el medio, capaz de señalar una frontera nítida entre la realidad y la ficción que libera a esta última de tener que responder ante la prime$\mathrm{ra}$, de ser responsable, de tenerse que regir por leyes que no sean las propias. Una propuesta de cierto margen de maniobra para escritor y lector que luego han retomado sus herederos (novelistas modernos y tardomodernos) hasta agotar sus posibilidades, con la novela total, con esa búsqueda de una autonomía absoluta que representa tan bien Macondo9: la novela como una esfera impermeable o una burbuja de jabón, nada porosa, con una legislación absolutamente propia que no hay por qué comparar -ahí cada uno pone un límite al viejo imperativo de la verosimilitud-con leyes más mundanas, por ese compromiso que asume el lector de suspender su incredulidad: la fe poética a la que se refería Coleridge que retoman para la informática Pimentel y Texeira ${ }^{10}$.

Escribe Ricardo Piglia en El último lector: "Hay siempre algo inquietante, a la vez extraño y familiar, en la imagen abstraída de alguien que lee, una misteriosa intensidad que la literatura ha fijado muchas veces. El sujeto se ha aislado, parece cortado de lo real"11. Una liberación que, trescientos años después de Cervantes, Ortega y Gasset encaja perfectamente en su propuesta filosófica, dándole a esa autonomía una función puramente metafísica en un engranaje mucho mayor. Ya no es solo la imagen del lector absorto, concentrado en la ficción, crédulo a lo que está leyendo: una metáfora del pacto ficcional. Es también el papel que esa lectura, que ese tiempo de ocio, tiene exactamente en la vida del lector: No porque le aporte algún tipo de conocimiento (solo resonancias vitales, dirá), sino porque esa inmersión es la mejor vía de escape a la realidad radical que es su propia vida: el deseo extravagante de Baudelaire, que le sirve a Ortega, en bruto, solo con la ocurrencia,

\footnotetext{
8 Cervantes (1998), p. 1217.

9 Cf. Vargas Llosa (1971), p. 547. Escribe: "El tiempo de Macondo es [...] finito, circular, dura lo que la realidad ficticia, no la antecede ni la sucede, acaba con ella."

10 Pimentel y Texeira (1995), p. 15. Escriben: "Cuando [los usuarios] entran en el mundo virtual, la profundidad de su grado de compromiso varía continuamente hasta que cruzan el umbral de la inmersión. A partir de ese momento, el mundo virtual los absorbe, del mismo modo que lo hace un libro. [...] Es la misma transposición mental que tiene lugar cuando nos quedamos atrapados en una buena novela o en un juego de ordenador."

11 Piglia (2005), p. 26.
} 
de ovillo desde el que ir sacando el hilo de su propuesta. Cuando le preguntaron dónde le gustaría vivir, cuenta Ortega, el francés contestó: “¡Ah, en cualquier parte! ¡En cualquier parte con tal que sea fuera del mundo!” 12.

Su filosofía, como también otras que pasaron por el decantador de la fenomenología en la primera mitad del siglo pasado, propone, para superar las tesis idealistas, pensar la vida de cada individuo no como un ser estático sino como un drama, un hacerse a sí mismo. El hombre no tiene naturaleza, no tiene un alma y un cuerpo, que son cosas, sino historia: un acontecimiento que le sucede a cada uno, que le va sucediendo desde una circunstancia determinada. Como si su vida fuera un papel en una obra de teatro que ya ha empezado cuando él aparece por primera vez y que continuará cuando él haya desaparecido. Mientras tanto, en ningún caso va a poder bajarse del escenario: mientras viva no tendrá más alternativa que interactuar con lo que lo rodea. Con lo que, en un sentido absoluto, como la solución metafísica a la necesidad de cada uno de descansar de tanto en tanto de su propia vida, es imposible la evasión. La vida es un quehacer que no se detiene. Pero, dice, de algún modo, de manera menos categórica, sí cabría la posibilidad de desconectar un momento, una evasión a otro mundo que no es real: el orbe irreal que crea sobre todo el arte, en el que uno mismo, en tanto que lector o espectador, se convierte también en irrealidad. El arte, dice, es irrealización: una abertura de irrealidad que se abre en el contorno real del hombre para, con ese horizonte irreal, hacerle negar su realidad. Es escamotear la realidad que le fatiga y oprime. Escribe en "Idea del teatro": "Mientras estamos leyendo una novela egregia pueden seguir funcionando los mecanismos de nuestro cuerpo, pero eso que hemos llamado 'nuestra vida' queda literal y radicalmente suspendido. Nos sentimos distraídos de nuestro mundo y trasplantados al mundo imaginario de la novela"13. Es un descanso, dentro de lo posible, para aliviar esa perpetua tensión dejando en suspenso su circunstancia para, de hecho, concentrarse en sí mismo, para ensimismarse gracias a la ficción y descansar de su entorno, de su vida, dice él, algo que no puede hacer ningún otro animal.

Pero en este punto se revela la ingenuidad del planteamiento. Como imagen, como metáfora, esa evasión es válida para explicar el estado del lector durante la lectura, en un argumento que luego puede tomar diferentes direcciones: al menos en estética, en ética o en epistemología. El problema, al hacer converger esta supuesta consecuencia de la lectura con la ontología, es que no tolera tan fácilmente la traslación desde lo metafórico a lo literal: Esa evasión no puede ser tal. Solo una expresión para referirse al lector absorto. Rebajadas, por tanto, sus pretensiones, consciente la imagen de su déficit filosófico, no puede apoyar su argumento de dos mundos, uno real y otro irreal, creado con la lectura, en un elemento físico que sirva de separación, de límite, de frontera. Pero Ortega, que pretende construir de verdad una

12 Ortega y Gasset (2009), tomo IX, p. 846.

13 Ortega y Gasset (2009), tomo IX, pp. 846-848. 
ontología para su razón vital, en este arrabal que es su estética no prescinde del elemento físico; aunque podría haberlo hecho.Echa mano del marco de un cuadro para separar arte y realidad, para remarcar visualmente la separación que necesita para ambos entornos: Hacia dentro el orbe fantástico, la irrealidad; hacia fuera, los hombres ocupados en vivir, la realidad. Sin posibilidad de mezclarse y confundirse, porque la percepción de la realidad vivida y la percepción de las formas artísticas, dice, son incompatibles. Como si la obra de arte fuera -la imagen es suya- una isla imaginaria que flota rodeada de realidad por todas partes.

Para una exposición más rigurosa, capaz de entender esta separación entre arte y realidad sin el objeto físico, sin el marco o el telón del teatro, la función de aislante del contorno vital solo podría darse desde el ensimismamiento que, para el propio Ortega, en otros trabajos suyos, es -también con una metáfora- esa retirada del mundo para meterse el hombre dentro de sí mismo, aunque sea el arte (una novela) lo que active ese mecanismo: lo que haga del lector un sonámbulo, lo que lo anestesie de la realidad, lo incomunique. Pero Ortega, más atento entonces a otras cuestiones, no hace explícita esa conexión entre ensimismamiento e inmersión que no habría requerido de ese marco tan problemático para certificar una realidad y una irrealidad como dos espacios diferentes e incomunicados. Con lo que deja unos cuantos arneses para retomar con la seguridad de las filiaciones la reflexión filosófica en torno a la virtualidad; pero todos ordenados desde la sola función de sumergir al usuario en la ficción, que él resuelve con la imagen de un elemento tangible, el marco. Un problema, de hecho, en su estética, sin querer llevar la crítica más lejos, por las dificultades que plantea para determinados géneros artísticos. Que, además, como el elemento neutro que separa tajantemente los dos mundos, no puede aplicarse de ningún modo a Internet, que no admite una separación tan ingenua entre uno y otro orden (como podría ser la pantalla del ordenador) que permita identificar claramente a cada elemento como real o no real (ficcional o virtual).

\section{Su traslación al internauta}

El punto de arranque de las distintas posiciones en torno a la virtualidad que se genera con la tecnología digital es -en la mayoría de los casos- su identificación con la simulación y, con esta, sin demasiado rigor, con la ficción y la no realidad, con el trabajo fundamental, muy seguido, de Sherry Turkle, La vida en la pantalla. La construcción de la identidad en la era de Internet, que publicó en $1995^{14}$. Virtual, de antiguo, es lo que tiene existencia aparente y no real: lo que produce un efecto, como si fuera real, sin ser real; cada vez más parecido gracias al trabajo de

14 Cf. Turkle (1997), p. 29. Su tesis primera para la evolución de la informática: "Nos estamos trasladando de una cultura modernista del cálculo a una cultura posmoderna de la simulación." 
los programadores, trasmitiendo en algunos casos las mismas impresiones, pero sin las consecuencias que tendría cada acción con las reglas de juego de la realidad. Como en los simuladores de vuelo, por ejemplo. Con lo que el problema para aquellos en los que prevalecen las objeciones, es que aquí no hay un marco, o un telón, una línea divisoria que, como en Ortega, determine claramente qué es lo real y qué es lo virtual, lo no real. Una y otra se confunden, se diluye una dentro de la otra, sin una delimitación clara, que hace perder a la realidad, dicen, consistencia ontológica, o al menos credibilidad. Pero para llegar a este razonamiento han necesitado previamente reducir las funciones de las simulaciones a una sola, o al menos a una sola consecuencia desde esa función que engloba todas las demás: generar una experiencia o un entorno virtuales sin (necesidad de) correspondencia con la realidad.

No tienen en cuenta las funciones epistémicas, o didácticas, del laboratorio que es esa realidad virtual 15 (como en la novela los egos experimentales de Kundera) ${ }^{16}$, porque en un plano anterior, en una reflexión que a la fuerza tiene que ser previa, les pesa más los riesgos del engaño al que puede llevar, intencionadamente o no, la aparición de realidades ficcionales que no remarcan su carácter ficcional, no real: no saber si es un laboratorio o si de hecho ha ocurrido con las consecuencias de su existencia. Una suspicacia de un perfil teórico bajo que se explica porque entienden que la virtualidad del entorno digital, al exigir del usuario -como se ha defendidoesa misma inmersión que la ficción, es equivalente a la ficción, con sus mismas funciones y autonomía (con un estatus ontológico menor, al menos como no realidad). Sin caer en que las aplicaciones informáticas abarcan con su virtualidad mucho más que la mera ficción, entendida en los términos clásicos, como la cosa fingida. Aunque pueda serlo en tanto que posibilidad de lo condicional, de lo que podría llegar a ser, al probar un modelo. Pero con otra perspectiva para la reflexión sobre la ficción que no puede ceñirse -con los usos y abusos de la posmodernidad sobre nuestra espalda- a si algo, cualquier cosa, es real o no lo es porque mire a la línea que delimitaría ambas de un lado o del otro.

Esta identificación de lo virtual con la simulación para Internet responde solo a un desconocimiento de su mecanismo interno y de sus usos, a la falsa concepción de Internet como espacio, como si hubiera en él una continuidad que permitiera, de verdad, navegar a través de él, con la otra metáfora acuática. Pero lejos de ser un territorio continuo, es -como ha escrito Ryan- una red bastante laxa hecha de enlaces y nudos, rutas y destinos, entre los que no hay nada17. Ese lugar que consideramos Internet en realidad solo tiene, como ha escrito Philippe Quéau ${ }^{18}$, una dimen-

\footnotetext{
15 El nuevo tipo de experimentación y predicción probabilitaria de la nueva acción tecnocientífica. Cf. Echeverría (2003), pp. 100-102.

16 Cf. Kundera (1987), pp. 156 ss.

17 Cf. Ryan (2004), p. 100.

18 Cf. Quéau (1998), p. 53.
} 
sión puramente lingüística, hecha de signos, que aumentan el lugar real que habitamos con los nuevos lugares virtuales que son -a pesar de esa otra concepción tan generalizada- fundamentalmente instrumentales, para comunicarse e informarse en un nuevo espacio social, no para inventarse una nueva identidad: Ese tercer entorno de Javier Echeverría de interacción e interrelación, que no es un hábitat, en el que no se vive, pero sí se actúa. Porque no existen esos límites, esa membrana hermética, que la comprensión de Internet como un mundo separado se impone a sí misma ${ }^{19}$. Al contrario: sabemos que lo virtual y lo real se afectan mutuamente en nuestra cultura, en la que vivimos ahora, que Manuel Castells ha llamado de la virtualidad real, en la que la realidad es capturada por completo en un sistema virtual cuyo contenido, a su vez, se convierte en la experiencia: "Es virtual -escribe- porque está construida principalmente mediante procesos virtuales de comunicación de base electrónica. Es real (y no imaginaria) porque es nuestra realidad fundamental, la base material con la que vivimos nuestra existencia, construimos nuestros sistemas de representación, hacemos nuestro trabajo, nos relacionamos con los demás, obtenemos información, formamos nuestra opinión, actuamos en política y alimentamos nuestros sueños. Esta virtualidad es nuestra realidad. Esto es lo que caracteriza a la era de la información: es principalmente a través de la virtualidad como procesamos nuestra creación de significado" 20.

Pero sigue ahí el temor de las posiciones más desconfiadas, atadas todavía a la noción de inmersión, ante la incorporación de Internet a lo cotidiano como una pieza más de nuestra realidad y de nuestra percepción de la realidad, con sus riesgos. Muy lejos de esa deificación de la tecnología que Postman denominó Tecnópolis ${ }^{21}$. Como si estos teóricos más reacios -los nuevos apocalípticos- tuvieran todavía muy presente la función que para Ortega tiene lo virtual: solo como evasión, un entretenimiento, hacer a uno olvidarse por un rato de sí mismo, de su vida, al sumergirse en otra realidad creada ex profeso. Sin trasvases posibles. Lo que los obliga -aquí, para la reflexión sobre la tecnología, un daño colateral- a separaciones tajantes entre uno y otro mundo, a la incomunicación y la imposibilidad de flujo entre ambos, sin las garantías, además, de un marco tan convincente como el de un cuadro. A que cualquier roce -en un plano ético desconcertante- no pueda ser entendido más que desde una voluntad de engaño: lo fallax de Agustín de Hipona: lo que siendo falso se hace pasar por verdadero. O peor: como la constatación de las tesis de Baudrillard mal encuadradas, un Baudrillard de frases contundentes pero sin acabar de contextualizar, sin su (también cuestionable) fondo epistemológico y ontológico: solo el del simulacro tecnológico extendiéndose y contaminándolo todo, como si este fuera el agente más que el síntoma.

19 Cf. Echeverría (1999), p. 170.

20 Castells (2001), p. 230.

${ }^{21}$ Cf. Postman (1994), p. 97. 


\section{Las simulaciones informáticas en el recorrido del simulacro}

A mediados del XIX el paso de la mímesis a la autorrepresentación como función primaria del arte refuerza su autonomía, con un recorrido que llegaría sin demasiados recodos hasta la primera mitad del siglo XX, hasta dar con esa asunción problemática de las vanguardias con el espacio social que la sociedad burguesa había reservado para el arte 22 . La modernidad estética apostó por separar arte y vida con la premisa de que el arte no tiene utilidad. En su Crítica del juicio Kant escribió de la finalidad sin fin del arte. Y Hegel de la liberación del arte de todos los servicios que había ido asumiendo, para así poder exponer la verdad. Provocan, con la expresión de Gadamer, su devaluación ontológica ${ }^{23}$. Hasta llegar al arte por el arte como el punto de partida ante el que reaccionan distintos movimientos de vanguardia rompiendo la membrana que quería proteger al arte de su entorno y, de paso, al entorno del arte.

Con la novela, en cambio, a pesar de haberse abierto otras vías que apuestan por una hibridación con la realidad misma, en el imaginario colectivo de novelistas y lectores -no de la crítica- sigue ocupando cien años después un lugar visible la imagen de la obra como espacio cerrado. En 1907, al tiempo que las vanguardias buscan un nuevo rumbo para otros géneros, Unamuno escribe en Niebla: "La cosa fue que un día surgió dentro de mí un pobre ente de ficción, un puro personaje de novela, un homúnculo que pedía vida. El pobrecito quería ser y existir. [...] Y fue mi pobre Homúnculo, mi Augusto Pérez -así lo cristiané o bauticé- el que rebulló en las entrañas de mi mente pidiéndome existencia de ficción"24. Como si la novela, también en su avanzadilla (lo de Unamuno, de hecho, es una nivola), no se sintiera tan claustrofóbica. Como si -es más- ese hermetismo fuera estructuralmente necesario, al menos, para posicionar al lector.

Para explicarla, siempre se acude a las mismas metáforas, las relacionadas con el territorio, con un espacio, o un mundo: la novela como un terreno que no es el que ocupa físicamente el lector y que, por tanto, le exige desdoblarse y ocupar también el nuevo espacio (no físico) que el autor -estirando la metáfora anterior- o crea o descubre. Volpi, un siglo más tarde que Unamuno, en 2008, escribe que el escritor es el que renuncia a la realidad y edifica otra; el que inventa un universo paralelo para que el lector lo habite, para que abandone su vida cotidiana y se traslade a esa prisión: un mundo aparte, con sus propias leyes, con algunas semejanzas con

\footnotetext{
22 Cf. Eagleton (2006), p. 59.

23 Cf. González Valerio (2010), p. 172. Escribe: "Salvar el arte de la mentira al catalogarlo como ilusión provoca una devaluación ontológica, porque el arte siempre queda marcado como lo no-real, su anverso es la 'suprema realidad'. La autonomía termina por encerrar a la obra en un reino ilusorio, en un 'cuasi-mundo'."

24 Unamuno (2000), p. 74.
} 
este pero con otra lógica. Escribe: "Es un demonio (casi un dios): me invita [como lector] a abandonar la realidad, mi realidad, para pasar a la suya, a su piel. Mientras leo, el novelista se apodera de mí, me invade, me posee. Leo y estoy endemoniado, no me pertenezco, me desgajo" 25 . Pero la imagen de la obra como mundo, muy atractiva como primer fogonazo, se agota antes de dar todas las respuestas sobre su génesis y sus inevitables fronteras, tanto si se toma la literatura solo como mímesis como si se recrea en su propia presentación. El origen de ese mundo tiene que ser, inevitablemente, este otro mundo que habita el lector en su vida cotidiana: no hay más sitios de los que alimentarse, aunque luego el elemento de origen permute infinitas veces. No hay posibilidad de un afuera. Lo que plantea, inmediatamente después, los problemas de la segunda cuestión, sobre sus límites, que entroncaría con las teorías del fin del arte, del fin del arte como hecho específico.

Decía Umberto Eco que el encanto de toda narración está en que encierra al lector o al espectador dentro de las fronteras de un mundo (otra vez la metáfora referida a la ficción) que es un parásito del real, al poner entre paréntesis una parcela de este mundo real y cerrarlo (al reducirlo de escala, diría Vargas Llosa), para poderse manejar con él y así poder interpretarlo, sabiendo que encierra un mensaje que un hecho concreto o una experiencia de esa realidad de la que se alimenta no tiene por qué tener ${ }^{26}$. Es lo que diferenciaría a la ficción de la realidad: la primera ordenada, proporcionada, lo que facilita su comprensión; y la segunda caótica e imprevisible, que necesita, al menos, una mirada retrospectiva, cierta lejanía, para poder ser interpretada. Pero ese cierre a veces no puede ser tan categórico (tan unívoca la frontera, dice Volpi), y es difícil concretar con qué elementos se puede suspender la incredulidad y con cuáles no. Lo que a veces es una cuestión inocente, casi un juego, muy frecuente en la última literatura. Pero otras veces, como escribe Eco, un problema importante: una confusión trágicamente preocupante27. Una reflexión que puede continuarse, con esta gradación de actitudes o de situaciones, en la tecnología digital e Internet. De hecho, Marie-Laure Ryan, en su recorrido por la historia de la simulación desde la literatura hasta los medios electrónicos, en seguida dio con los nuevos quijotes de la era electrónica, los que sirven de argumento, con tantos titulares, a los apocalípticos: las historias que se escuchan sobre gente que sufre el síndrome del mundo alternativo, con pérdida de equilibrio, sensación de malestar y amnesia corporal general cuando deja los sistemas de realidad virtual, los adictos a los juegos de rol sincrónicos, o niños con traumas emocionales por la muerte de una mascota virtual 28 .

\footnotetext{
25 Cf. Volpi (2008), pp. 29-40 y 205-206.

26 Cf. Eco (1996), pp. 94-95.

27 Eco (1996), p. 132.

28 Ryan (2004), p. 27.
} 
Aunque esta sería una cuestión menor, con pocos casos, que puede abordar la psicología y la psiquiatría. Para los filósofos más suspicaces con la tecnología digital -como Paul Virilio, para el que la realidad virtual era tan peligrosa como las cabezas nucleares- el peligro real, la amenaza, estaría, en lo epistémico, en las facilidades que la electrónica da al mentiroso con la manipulación de las imágenes, dándole más poder si no se llegan a establecen unas reglas del juego que parecen poco factibles: las que reclamaba, por ejemplo, Dominique Wolton, que ya en 1999 exigía que se marcase en la recepción una diferencia radical entre la imagen de la realidad y la imagen de una realidad virtual con esas reglas consensuadas todavía por establecer ${ }^{29}$. Para estos, entonces, el usuario no se engañaría a sí mismo, como lo hacen los quijotes de Ryan -no sería este el problema-, sino que sería engañado con el entorno virtual y, con este, con los nuevos medios de comunicación, al no saber ante qué plano ontológico se encuentra: si uno completamente real o en parte virtual, con imágenes que no son reales (que no responden a la realidad). La realidad -se lamentan los críticos del Internet hecho mundo- se debilitaría al romperse esa frontera que veían tan clara Cervantes y Ortega y que también ven clara ellos.

Pero la nueva tecnología y una reflexión menos ingenua sobre la realidad han acabado con los perfiles nítidos de una y otra que estos teóricos quieren conservar como armazón para sus críticas. Ficción y realidad, en el mejor de los casos, sabemos ahora que no se diferencian. O como en el mapa exacto de los cartógrafos de Borges que llegó a recubrir el territorio que representaba. $\mathrm{O}$, sin territorio siquiera, en la propuesta de Baudrillard. Aunque sea Baudrillard la cita recurrente de estos críticos de Internet al merodear a tientas la noción de mundo, a vueltas con su autonomía. Pero, por eso mismo, por ese orden de posiciones incoherente que ahora explico, es también otro frente desde el que rebatir el argumento estándar que, como crítica de Internet, parte de la metáfora de la inmersión: del usuario sumergido en la red, sin capacidad para discernir lo real de lo que no lo es. Muy lejos de la propuesta del simulacro, en la que la inmersión no es posible, porque no hay a un tiempo dos mundos diferentes para que el usuario pueda pasar de uno a otro (a no ser que se entienda ese paso como etapa histórica, para una colectividad, no para un individuo). Porque lo que plantea Borges -con el cuento que marcaría el nivel de confusión que sostienen estos críticos que se da en la relación de Internet con lo real- es, para Baudrillard, solo un paso anterior, que se queda corto, camino de la hiperrealidad, para la que el territorio ya no precede al mapa ni lo sobrevive: en adelante -escribe Baudrillard- será el mapa el que preceda al territorio y el que lo engendre; toda percepción -vuelve categórico- pasa por el velo del simulacro.

El simulacro -hecho también con las escenas de la ciencia ficción- es la apoteosis apocalíptica de los que han decidido mantenerse alerta ante la tecnología digital. Pero al insertar de nuevo en el texto completo esas referencias puntuales suyas

29 Wolton (2000), p. 49. 
a Baudrillard para devolverles íntegro su sentido, queda patente el distinto nivel de radicalidad en el que se mueven uno y otros: A partir de su reflexión de las cuatro fases de la evolución de la imagen se revela que si Baudrillard apuesta por la última de estas para la situación actual -“[La imagen] no tiene relación con ningún tipo de realidad: es ya su propio y puro simulacro"-, la recriminación de estos teóricos que se amparan generalmente en él, o al menos lo citan como próximo, encajaría mejor en la segunda fase -"Enmascara y desnaturaliza una realidad profunda"-, que trasmite todavía una confianza fuerte en una realidad sólida que, al menos, se puede recuperar 30 . Entre Baudrillard y estos otros teóricos hay en medio una fase de la imagen que estos todavía no han recorrido, o que pasan por alto: "Enmascara la ausencia de realidad profunda". Muy lejos (con una posición metafísica diferente) uno de los otros. Porque los simulacros del posmoderno Baudrillard no se fabrican, ni se utilizan para engañar. Son el síntoma de un seísmo mucho más radical que la mera posibilidad de confundirse uno con las simulaciones informáticas: Es una condición epistémica global de nuestro tiempo, de la hiperrealidad: "El simulacro no es lo que oculta la verdad. Es la verdad la que oculta que no hay verdad. El simulacro es verdadero" 31 . En cambio, estas críticas o temores hacia las posibilidades perversas de la nueva era digital estarían referidas, como el cuento de Borges de los cartógrafos, a los simulacros de segundo orden: una fábula caduca para nosotros, escribe Baudrillard ya en 1978, marcando las distancias: "El momento crucial se da en la transición desde unos signos que disimulan algo a unos signos que disimulan que no hay nada"32. Con un antes y un después que estas críticas no han recorrido, porque apoyan sus temores en la concepción de los medios digitales como otro mundo, pero sin hacer desaparecer o constatar la desaparición del otro mundo que sería lo real: el otro extremo de la comunicación con los medios. Lo que para Baudrillard sería más bien ideología, no simulacro: "La ideología -escribe- no corresponde a otra cosa que a una malversación de la realidad mediante los signos, la simulación corresponde a un cortocircuito de la realidad y a su reduplicación a través de los signos"33.

La tecnología digital ha permitido muchos de los pasos que previó Baudrillard: ha hecho cotidiano el manejo de unas herramientas que alejan (que permiten alejarse) al usuario de la realidad concreta, física, con la que interviene. Pero los trabajos fundacionales de Baudrillard no son la reflexión directa sobre las posibilidades técnicas de esta nueva tecnología, muy primitiva a finales de los 70 , cuando escribe algunos de sus títulos más recurridos. Hay que tener cuidado al forzarlos. Las simu-

\footnotetext{
30 González Quirós (1998), p. 74. Escribe: "El entorno sensorial en el que hemos madurado, lo que estimamos nuestro mundo, se eclipsará frente a un sistema que reconstruye e interpreta la realidad de otro modo."

31 Baudrillard (2000), p. 36.

32 Baudrillard (2005), p. 18.

33 Baudrillard (2005), p. 57.
} 
laciones informáticas, aunque enfilan el mismo camino, no son los simulacros que, en su exposición, constituyen lo hiperreal, el crimen perfecto, que sería una nueva era, la de la simulación, que se abre con la liquidación de los referentes reales y su resurrección artificial en los sistemas de signos: "No se trata ya de imitación, ni de reiteración, incluso ni de parodia, sino de una suplantación de lo real por los signos de lo real, es decir, una operación de disuasión de todo proceso real por su doble operativo" 34 . El signo sustituye a la referencia real. El modelo precede al hecho. Con la simulación ya no se plantea el problema de la verdad o de la realidad de este mundo: el signo hace desaparecer la realidad y, al tiempo, enmascara esa desaparición ${ }^{35}$. El crimen perfecto de Baudrillard no son los temores por el engaño, por el peligro de la alienación, por la confusión de la sombra; sino la ultra-realidad, la transparencia, el exceso de realidad con el avance de la información y la comunicación 36 .

\section{La inmersión como noción problemática}

Pero, centrados en ese segundo nivel en el que se quedan las críticas referidas a los medios de comunicación digitales, se hace patente que el uso metafórico del término de la inmersión (que implica una autonomía y un hermetismo, una incomunicación entre elementos o estados) deriva en un planteamiento falaz, más allá de la licencia poética, si uno se propone enraizarlo de verdad en esa imagen. Porque esa inmersión supone, literalmente, introducirse uno mismo o introducir a otro en un líquido o, al menos, relajando el sentido del término, en un espacio diferente. Es dejar de estar en un espacio, en un sitio, para pasar a otro y quedarse dentro de él: como en Neuromante y Matrix, en un contexto digital, por ejemplo, pero también como en Alicia en el País de las Maravillas y El mago de Oz. Porque la inmersión, como la evasión de Ortega o el ensimismamiento (que también es una metáfora), denota un lugar al que primero se llega y en el que después se permanece. Una cuestión arquitectónica de dentros y fueras, que justifica una decadencia, una escala degradada que va de un afuera veraz a un adentro ilusorio: el interior solo como un espacio menor, sin repercusión, poco fiable: un poner entre paréntesis, como decía Ortega. Como en la caverna de Platón, a la que vuelven todos, porque presenta a la imagen, en el interior de la gruta, como una entidad ontológica menor que la cosa real (que está fuera), y, en muchos casos, perversa, por ser copia inexacta (la sombra) de una realidad inteligible que puede tomarse, si no hay un ejercicio filosófico previo, como la realidad misma; como en Matrix, una de sus últimas actualizaciones más exitosas, en el que también -como ha indicado Žižek- el Elegido, como el

\footnotetext{
34 Baudrillard (2005), p. 11.

35 Baudrillard (2000), p. 15.

36 Baudrillard (2000), p. 53.
} 
que consigue desatarse y salir de la caverna, es el único capaz de ver que la realidad cotidiana es solo un universo virtual codificado ${ }^{37}$.

Para Internet pocos han querido pasar por alto la analogía con la caverna platónica, que en último término también implica una inmersión (previa). Se les presenta inevitablemente como un espacio propio, separado. De lo que concluyen que ese lugar tiene que ser diferente del que ocupa el usuario antes de interactuar en la red: Si el usuario está en la realidad, ese otro lugar debe ser -sin entrar en mayores consideraciones ontológicas- no-realidad (o, complicando menos la cosa, no-espacio, como lo han llamado también): una no-realidad que está compuesta no de cosas (que se ubican en la realidad) sino de imágenes que, como tales, en tanto que son una representación de una cosa, una reproducción que está sustituyendo a la cosa, pueden tener dos referentes: uno real y otro falso (fake), en tanto que no forma parte de lo real. Ambos con el mismo poder para embaucar al internauta confiado, incapaz de distinguir las imágenes con referente real de las imágenes con referente no real una vez inmerso en el espacio cerrado de Internet: El punto de partida del argumento más básico para arremeter contra la virtualidad de Internet, o al menos para mantenerse suspicaz.

Con lo que Internet hereda así del arte su posición de objeto de una reflexión de muchos años sobre sus posibilidades y los temores que alimenta; que desde la perspectiva idealista -de oposición de contrarios, de escisiones- de estas críticas lo suponen como un mundo virtual que es una sustitución (y una amenaza) del real, independientes uno y otro, con la pesada carga detrás de la dicotomía entre original y copia que Molinuevo, en su Humanismo y nuevas tecnologías, localiza en la cultura occidental de raíz platónico-cristiana que, ya con el mito de la caverna, muestra al hombre como prisionero de las imágenes ${ }^{38}$.

Aunque como alternativa a la antinomia de lo virtual y lo real tenemos la convivencia no problemática e, incluso, la integración de ambos mundos ${ }^{39}$. El ciberespacio barlowiano frente al ciberespacio gibsoniano 40 . Entender Internet (y otras aplicaciones informáticas) no desde la imagen (que en el mejor de los casos toma su valor de su referencia), como una reproducción, como una copia de la realidad, sino como mediador (el que intercede, intentando conciliar dos intereses o dos posturas) para la percepción y la interacción con la realidad misma, sea esta lo que sea. La postura en España de Castells, Echeverría o Molinuevo, por ejemplo. Una adaptación para Internet de la propuesta de Iser para el arte, para el que piensa la rela-

\footnotetext{
37 Cf. Žižek (2006), pp. 175-206.

38 Cf. Molinuevo (2004), p. 223.

39 Cf. Molinuevo (2004), p. 33.

40 Cf. Molinuevo (2006), pp. 52-53. Escribe: "El ciberespacio gibsoniano es una matriz de datos virtual que crea la apariencia de un mundo real. En el segundo, lo virtual está perfectamente integrado en lo real."
} 
ción entre la ficción y lo real no en términos de oposición, como antítesis, sino en términos de comunicación, en tanto que la ficción dice algo sobre la realidad. Más atento al despertar del lector en la realidad que a su inmersión en la irrealidad41.

Sin necesidad de metáforas que coloquen una frontera entre ambos: Sin la imagen de la inmersión, que impide cualquier integración de ambos elementos con esa evocación a un lugar distinto del que uno se encuentra, que emparenta con una terminología espacial que se ha cargado de nuevos significados al cubrir también a Internet, como entrar, bajar, navegar (o surfear en inglés), o, la última, la nube. Sino al contrario: Al rebufo de las teorías acerca del final de los límites bien definidos que tienen tanta fuerza ahora para casi cualquier ámbito: Lo que Jameson, en su exposición de la posmodernidad, enmarca en la destrucción (ya incuestionable) de esa cuasi-autonomía de la cultura a manos de la lógica del capitalismo avanzado, que la ha esparcido, en buena medida con los medios de comunicación, en todos los ámbitos de la vida social42.

\section{La lección aprendida del arte, para su convergencia con Internet}

Un camino, este del fin de la autonomía, que el arte, quizá como ningún otro ámbito, ya ha recorrido, de principio a fin, pausadamente, a lo largo de mucho tiempo, pero con los acelerones finales de un nuevo cambio de siglo -como lo fue también el tiempo de las vanguardias-, determinado por la tecnología. En los primeros años del siglo XX, la autonomía del arte fue de la mano de un arte más auténtico, más puro; también más minoritario, reservado solo a los más capacitados para comprenderlo. A Ortega las vanguardias le interesaron únicamente como síntoma de esta división entre artistas y no artistas, nada más, con lo que despachó rápido sus características propias, en que mezcló sin rigor distintos movimientos muy alejados entre sí. Bordieu entendió el arte -cada vez más exigente, decía- como una práctica enclasante, que servía, como pocas, para distinguirse socialmente 43 . Y Greenberg, en su defensa del expresionismo abstracto americano, creó dos bandos: tomó del alemán el término kitsch como referencia peyorativa de un arte de consumo, mayoritario, poco exigente, y lo ubicó enfrente, enfrentado, a este arte vanguardista, el genuino de su tiempo, para ilustrar su argumento de la pasividad: frente a lo exigente que es para el espectador el arte de vanguardias, que se ha vuelto extraño a lo social al hacerse cada vez más autónomo, observa lo digerible que es el arte de masas -su gran baza-, que incita a la recepción pasiva a este modelo de espectador consumidor. Uno es reflexivo; el otro imitativo. Uno es introvertido; el otro

\footnotetext{
41 Cf. Iser (1987), pp. 224-225.

42 Cf. Jameson (1991), pp. 105-108.

43 Cf. Bordieu (1998), pp. 16-28.
} 
extrovertido. Uno es autónomo y puro; el otro heterónomo e impuro. Uno y otro para su clasificación dependen, al final, de su capacidad para hacer reflexionar y conseguir una respuesta activa del espectador: Un criterio con cierta vigencia todavía en muchas estéticas. Pero que también ha tenido una respuesta, legítima y muy potente, como la de Noël Carroll44, del lado del arte de masas, que destaca, una vez agotada la modernidad, las perversiones de un arte autónomo: Primero -lo más inmediato- en el ámbito social. Y luego, con sus características intrínsecas, en un plano ontológico, con el que se vuelve a formular la pregunta sobre qué es el arte, más receptivas ahora las teorías a las relaciones que se establecen para constituirse como arte que a límites autoimpuestos. Lo que agotaría totalmente, en esa deriva ontológica, la imagen de la inmersión referida al arte, como un modo de recibirlo, de ser influido por él.

De este lado, en el camino que puede recorrer igualmente la valoración y uso de la tecnología digital, la estética pragmatista, desde Dewey, propone recuperar la continuidad entre la experiencia estética y los procesos normales de la vida para acabar con la concepción compartimental del arte, que lo envió en su día a un reino aparte y, con esto, lo eliminó de la vida de la mayoría de la población. Propone, para nuestro tiempo, sacar el arte otra vez a la esfera de la vida diaria: acabar con la distinción, perniciosa para los pragmatistas, entre el negocio y el ocio: entre el trabajo práctico y la experiencia estética, considerada como anestésica e irrelevante, como aparece en el prólogo del Quijote. Porque, como ha escrito Richard Shusterman, esa separación pudo tener sentido en su momento, para liberar al arte de su función tradicional de ayudar a la ideología de la Iglesia y la corte, pero ya no hay razones convincentes para ese aislamiento impuesto por esta otra ideología establecida del arte autónomo: "Su rígido aislamiento de la praxis de la vida para preservar su pureza ya no es provechoso y ni siquiera creíble" 45 . Unos postulados básicos, de arranque, desde los que Bourriaud ha propuesto su nueva estética, una estética relacional, no referida a objetos sino a intervenciones sociales: "Si observamos las prácticas contemporáneas, más que las formas, deberíamos hablar de formaciones, lo opuesto a un objeto cerrado sobre sí mismo por un estilo o una firma. El arte actual muestra que solo hay forma en el encuentro, en la relación dinámica que mantiene una propuesta artística con otras formaciones, artísticas o no"46. Un camino que ya habían abierto para el libro Deleuze y Guattari, con su noción del rizoma, que acaba con la comprensión del libro como un objeto (cerrado, autónomo) producido por un sujeto. El libro -escriben- está hecho de materias diversamente formadas, de fechas y velocidades muy diferentes: "En un libro, como en cualquier otra cosa, hay líneas

\footnotetext{
44 Cf. Carroll (2002).

45 Shusterman (2002), p. 189.

46 Bourriaud (2006), p. 22.
} 
de articulación o de segmentaridad, estratos, territorialidades; pero también líneas de fuga, movimientos de desterritorialización y de desestratificación"47.

Para Bourriaud, ante el riesgo de que precisamente los nuevos medios de comunicación conviertan al individuo solo en consumidor, con un único trayecto posible en las autopistas de la información recién creadas, este arte busca nuevos espacios y nuevas relaciones en los márgenes de la comunicación para dar alternativas, como universos posibles. Sin la ambición de los artistas anteriores, sin la pretensión de un cambio global, sino de pequeñas intervenciones, sin salirse de las preocupaciones cotidianas. Lo que para la novela (y también la poesía) ha hecho recientemente -con un eco mediático excepcional- Fernández Mallo, justificando esa lejanía de los principios autónomos de Cervantes con un aparato teórico suficientemente sólido detrás, deudor del propio Bourriaud: Como respuesta a la infosaturación, al exceso de información que han traído los nuevos medios de comunicación, Mallo ha propuesto para la literatura la estetización del spam: convertir en artístico, en elementos literarios, la basura informativa, la información que en el momento determinado de recibirse no se consideró útil (unas frases sueltas de una conversación oída, por ejemplo) pero que puede ser reciclada para el arte, como otro modo más audaz de apropiacionismo, para forzar los límites de lo artístico hasta cuestionarlos inmisericordemente ${ }^{48}$. Hasta hacer inviable cualquier pretensión de autonomía, de ser un mundo aparte. Porque ese spam en la obra literaria de Fernández Mallo se organiza -análogamente a cualquier mecanismo informático- como una lista, como si en una columna se enumerasen los distintos fragmentos; sin tener que forzar una relación (una historia, una trama) entre ellos que haga posible una lectura ininterrumpida, absorbente, capaz de sumergir al lector en la ficción con la intensidad de la novela canónica.

El mecanismo propuesto por Mallo es otro que el de la novela moderna: De una confrontación constante con la realidad, al tomar sus elementos y modificarlos (convertirlos en ficción) con diferente intensidad: en algunos casos solo como nota informativa, como documento, tal como los ha recibido el autor, y en otros completamente alterados, en una sucesión que es un juego de combinaciones que remite a las operaciones informáticas: que la novela sea abierta, disgregada en el espacio y el tiempo y desestructurada, con las características que da Vicente Luis Mora para la novela posmoderna 49 . Un híbrido de la literatura con las nuevas herramientas digitales que intenta sacarle rendimiento a las posibilidades combinatorias del hipertexto, aunque sea en papel, forzando al máximo los límites de la novela al multiplicar ilimitadamente sus relaciones con el exterior, al fagocitar, de hecho, lo extratextual hasta convertirlo todo en un (potencial) único texto.

\footnotetext{
47 Deleuze y Guattari (1994), p. 9.

48 Cf. Fernández Mallo (2009b), p. 80.

49 Cf. Mora (2007), pp. 29-30.
} 
En su Poética Aristóteles decía de la trama que era lo que tiene un principio, un medio y un final: las historias bien estructuradas no debían ni comenzar ni finalizar al azar. El hipertexto (como nuevo género literario, también llamado hipernovela o hiperficción) quiere lo contrario: con la definición de Ted Nelson de 1965, una escritura no secuencial, un texto que se bifurca: un modo de organizar un texto en el que el escritor debe especificar qué secuencias de lectura están disponibles en cada momento para que el lector, en la medida de lo posible libremente, se decida por una. Como si fueran bloques de texto conectados entre sí por nexos para formar distintos itinerarios. Con esa referencia lejana a otro cuento de Borges: "Yo me había preguntado de qué manera un libro puede ser infinito. No conjeturé otro procedimiento que el de un volumen cíclico, circular. Un volumen cuya última página fuera idéntica a la primera, con posibilidad de continuar indefinidamente" 50 . Fascinante en sus posibilidades: mucho más cerca de la vida misma, como ha escrito Yellowlees Douglas, porque es imprevisible 51.

Aunque nos quede la advertencia de Kant de que la auténtica tarea crítica está no tanto en aumentar el caudal del conocimiento como en saber liberarse de los errores, por muy queridos que estos sean: Que la hipernovela fuera en su día un fracaso rotundo, a pesar de las posibilidades que el hipertexto ofrece para crear historias, tiene que ser -con la frase hecha retomada con su nuevo sentido- un aviso a navegantes.

Pero aquí sirve también de argumento último -en tanto que revela exactamente el mecanismo de Internet-. Si esa imagen de la inmersión funcionó en muchas tesis pioneras como explicación del acceso propio a Internet porque antes había encajado bien con la novela moderna, en este punto en que convergen literatura e Internet, en el que el hipertexto, como género literario, hace imposible o al menos dificulta mucho la analogía de la inmersión del usuario lector, se evidencian también las deficiencias de la inmersión como explicación de la relación del usuario con el soporte informático hipertextual, en un ámbito más amplio que lo puramente literario, tal como lo ideó Ted Nelson, como un modo de enlazar información. Porque el hipertexto exige al lector una atención al propio aparato físico con el que interactúa (la pantalla, el ratón, el teclado, etc.), que es un estorbo para poder ensimismarse con la ficción, con la historia que cuenta ${ }^{52}$.

Para que la inmersión fuera posible debería desaparecer ese entorno sensorial, esa mediación continuamente presente, y evitar lo que Faulth llamó bofetadas en la cara. Lo que escribe Stuart Moulthrop: "Si el propósito de la literatura es enriquecer al lector a través del influjo de una mente poderosa, la lectura debe ser absor-

50 Borges (1989), p. 477.

51 Cf. Douglas (2006), p. 215.

52 Aunque desde hace tiempo se augura el final de estas interfaces tan incómodas. Cf. Negroponte (1995) p. 124. 
bente y apasionante, capaz de captar la atención durante largos periodos. Los cambios tecnológicos solo pueden dificultar este proceso. Pretender que los lectores se pasen horas frente a la pantalla es pedirles demasiado. Molestar al lector con los enlaces hipertextuales interrumpe la transacción continua de las ideas"53. En un nivel básico de la reflexión metaliteraria, la participación del lector, que funciona como una de las consignas del arte contemporáneo, acaba a la fuerza con la coherencia narrativa del texto, que en la novela moderna cerraba su autor único. Pero acaba también con la confianza en un referente extratextual y sólido que no tiene cabida en un ambiente fluido en constante reconfiguración, que relega el contenido ficcional a un segundo plano. El lector da por hecho, entonces, que ese mundo que apoya como referente al texto no existe más que como actividad semiótica, y, como ha escrito Marie-Laure Ryan, pierde toda posibilidad de inmersión 54 . No hay mundo en el que sumergirse.

El campo de acción de la metáfora de la inmersión tiene un solo referente claro: La madeja de la tecnología digital va devanando el hilo en los diferentes ovillos de la teoría que la acompaña, y entendidos Internet como un sistema de enlaces y la realidad virtual como una simulación, sin mezclarlos en un todo tecnológico difuso, la inmersión queda a la fuerza recluida como metáfora solo para el segundo ovillo que, con un potencial enorme en su efecto para el usuario, es el que continúa -aunque es solo una de sus posibilidades- el recorrido que la novela llamada posmoderna decidió abandonar: esa mesa de trucos donde cada uno puede llegar a entretenerse sin daño de barras que escribe Cervantes en su prólogo a las Novelas ejemplares 55 .

\section{Referencias bibliográficas}

Aristóteles (2004): Poética, Madrid, Alianza Editorial.

BAUDRILlARD, J. (2005): Cultura y simulacro, Barcelona, Kairós.

BAUdrillard, J. (2000): El crimen perfecto, Barcelona, Anagrama.

Bordieu, P. (1998): La distinción. Criterio y bases sociales del gusto, Madrid, Taurus.

Borges, J. L. (1989): "El jardín de los senderos que se bifurcan”, en Obras Completas I, Barcelona, Emecé.

Bourriaud, N. (2006): Estética relacional, Buenos Aires, Adriana Hidalgo editora. CARroll, N. (2002): Una filosofía del arte de masas, Madrid, Visor.

CAstells, M. (2005): La era de la información. La sociedad red, Madrid, Alianza Editorial.

53 Moulthrop (2006), p. 161.

54 Cf. Ryan (2003), p. 118.

55 Cervantes (2000), tomo I, p. 52. 
Castells, M. (2001): La galaxia Internet, Barcelona, Areté.

Cervantes, M. (1998): Don Quijote de la Mancha, Madrid, Crítica.

Cervantes, M. (2000): Novelas ejemplares, Madrid, Cátedra.

Deleuze, G. y Guattari, F. (1994): Mil mesetas. Capitalismo y esquizofrenia, Valencia, Pre-textos.

Douglas, J. Y. (2006): "La red intencional", en Vilariño Picos, M. T. y Abuín González, A. (ed.), Teoría del hipertexto. La literatura en la era electrónica, Madrid, Arco Libros.

Eagleton, T. (2006): La estética como ideología, Madrid, Trotta.

Eco, U. (1996): Seis pasos por los bosques narrativos, Barcelona, Lumen.

ECHEVERRÍA, J. (2003): La revolución tecnocientífica, México DF, Fondo de Cultura Económica.

ECHEVERRÍA, J. (1999): Los Señores del aire: Telépolis y el Tercer Entorno, Barcelona, Destino.

Fernández Mallo, A. (2009a): Nocilla Lab, Madrid, Alfaguara.

Fernández Mallo, A. (2009b): Postpoesía. Hacia un nuevo paradigma, Barcelona, Anagrama.

GonZÁlez QuiRós, J. L. (1998): El porvernir de la razón en la era digital, Madrid, Síntesis.

González Valerio, M. A. (2010): Un tratado de ficción. Ontología de la mímesis, México DF, Herder.

ISER, W. (1987): El acto de leer, Madrid, Taurus.

JAMESON, F. (1991): El posmodernismo o la lógica cultural del capitalismo avanzado, Barcelona, Paidós.

Jauss, H. R. (2002): Pequeña apología de la experiencia estética, Barcelona, Paidós.

KunderA, M. (1987): El arte de la novela, Barcelona, Tusquets.

Molinuevo, J. L. (2004): Humanismo y nuevas tecnologías, Madrid, Alianza Editorial.

Molinuevo, J. L. (2006): La vida en tiempo real. La crisis de las utopías digitales, Madrid, Biblioteca Nueva.

MorA, V. L. (2007): La luz nueva. Singularidades en la narrativa española actual, Córdoba, Editorial Berenice.

Moulthrop, S. (2006): "Retroceder: la vida y la escritura en el espacio roto", en Vilariño Picos, M. T. y Abuín González, A. (ed.): Teoría del hipertexto. La literatura en la era electrónica, Madrid, Arco Libros.

Negroponte, N. (1995): El mundo digital, Barcelona, Ediciones B.

ORTEGA Y GASSET, J. (2009): "Idea del teatro (una abreviatura)", en Obras completas (tomo IX), Madrid, Taurus.

Piglia, R. (2005): El último lector, Barcelona, Anagrama. 
Pimentel, K. y TexeIRA, K. (1995): Virtual Reality. Through the New Looking Glass, Nueva York, Intel/McGraw-Hill.

Postman, N. (1994): Tecnópolis, Barcelona, Círculo de Lectores.

QuÉAU, P. (1998): "La presencia del espíritu", Revista de Occidente, 206, pp. 43-53.

RYAN, M. L. (2003): "Inmersión o interacción: realidad virtual y teoría literaria", en Vega, M. J. (ed.), Literatura hipertextual y teoría literaria, Madrid, Marenostrum.

RYAN, M. L. (2004): La narración como realidad virtual. La inmersión y la interactividad en la literatura y en los medios electrónicos, Barcelona, Paidós.

SHuSterman, R. (2002): Estética pragmatista. Viviendo la belleza, repensando el arte, Barcelona, Idea Books.

TuRKLE, S. (1997): La vida en la pantalla. La construcción de la identidad en la era de Internet, Barcelona, Paidós.

Unamuno, M. (2000): Niebla, Madrid, Cátedra.

Vargas Llosa, M. (1971): García Márquez. Historia de un deicidio, Barcelona, Barral Editores.

VArgas Llosa, M. (2002): La verdad de las mentiras, Madrid, Alfaguara.

VolPI, J. (2008): Mentiras contagiosas, Madrid, Páginas de Espuma.

Wolton, D. (2000): Internet ¿y después?, Barcelona, Gedisa.

ŽıžEK, S. (2006): Lacrimae rerum, Madrid, Debate.

Enrique Ferrari Nieto

Departamento de Ciencias de la Educación

Facultad de Formación del Profesorado

Universidad de Extremadura

eferrari@unex.es 